\title{
Social Network Analysis Approaches for Social Learning Support
}

\author{
Daniel Amo Filvà \\ Universitat Politècnica de Catalunya \\ Av. Bac de Roda 19B \\ 08915 Badalona, Spain \\ danielamo@gmail.com
}

\author{
Francisco J. García-Peñalvo \\ University of Salamanca \\ Paseo de Canalejas, 169 \\ 37008 Salamanca, Spain \\ fgarcia@usal.es
}

\author{
Marc Alier Forment \\ Universitat Politècnica de Catalunya \\ Building Omega, Office 1116 \\ 08024 Barcelona, Spain \\ marc.alier@upc.edu
}

\begin{abstract}
Considered as a branch of learning analytics, social network analysis is the actual procedure allowing us to study interactions and relations between individuals in a social network. Given that educational roles need reliable methods to understand and optimize their social learning environment, it seems clear that social network analysis is the best suited approximation. Despite the abovementioned, very few learning management systems integrate these kinds of tools to help teachers and students enhance their social learning processes. The aim of this paper is to encourage learning management systems engineers to integrate (as default) tools for social network analysis. This way, social network analysis is presented in its fundamentals and applicability to different social learning situations. Moreover, researchers are also encouraged to work on easy models of use for both teachers and learning management system engineers.
\end{abstract}

\section{Categories and Subject Descriptors}

G.2.2 [Discrete Mathematics]: Graph Theory. K.3.1 [Computers and Education]: Computer Uses in Education.

\section{General Terms}

Design, Experimentation, Theory, Standardization.

\section{Keywords}

Social Network Analysis, learning analytics, social learning, graph theory.

\section{INTRODUCTION}

Since web 2.0 and social technologies have been integrated into the educational system, many researching efforts have been done in order to understand and optimize these online virtual environments of learning and education. The evolution of these virtual learning environments (VLE) to more social ones, such as those introduced by the Ivy League MOOC generators [1] that have rapidly extended throughout universities around the world [2], is the most irrefutable fact of the integration and disruption that social and web 2.0 technologies have caused in learning and educational processes, notwithstanding the potential benefits of social collaboration among peers [3], for example.
In addition, this social feature creates the need for new methodologies of social learning analysis to help understand and improve the learning scape within. Based on the aforementioned, new approaches to learning analytics or educational data mining [4] appear, that empower both teachers and learners in their roles. On one hand, teachers are able to understand and optimize learning processes within their courses. On the other hand, students can have a better tutor and a more efficient and personalized learning [5]. Thus, in order to analyze social learning environments, a social analysis method is needed [6]. SNA is considered a branch of learning analytics and the main methodology to accomplish the empowerment mentioned above [7].

Despite the importance of SNA in learning environments, there is a clear lack of this feature in most of the current LMSes such as Moodle, BlackBoard, EdModo or Schoology. Even though there is a community of developers behind these LMSes, there are quite few plugins available for the use of social analysis in social technologies, such as forums [8] or wikis, and not all of them are suitable for the latest versions of the LMSs. At the same time, there are some external tools that can make up for this need, such as SNAPP or Gephi [9-11], but there is a real demand of integrating these types of social analysis tools inside LMSs as a default feature [12].

This article aims to offer an overview of social network analysis fundamentals, their actual situation in regarding to education and use in online learning situations, by exposing different approaches to research. In order to accomplish this, the article is split into three parts; the first part gives a brief introduction to the SNA, its origins and its actual situation in relation to education; next, a short presentation of its fundamentals and categorizations in order to understand the whole concept; and finally, selected case studies and research is presented and organized by possible educational situations that can be optimized using SNA.

\section{INTEGRATION INTO EDUCATION 2.1 Brief origins of SNA}

Social Network Analysis, in relation to network theory, has its origins in sociology and has been used quite recently to analyze student interactions in educational environments [13]. In this aspect, there is much more practical use of the available social theories and methodologies than a reformulation and optimization of these. Despite this, some research and new approaches to social network analysis have been proposed by different authors, such as the conducted to optimize statistical models [14].

SNA is not a new method. SNA has existed since the 1930's with the main objective of studying different social structures [7] and relationships between the members. Some authors denote that it "provides a rigorous and standardized framework for analyzing 
internal communication patterns among individuals and groups" [7].

Since Moreno released the pioneering sociometric theory in 1934, and the underlying sociomatrix and sociogram [7], many scholars have worked on different aspects of social analysis. Starting in the late 1970's, the activity in the academic world has increased rapidly [15]. The main reason for this increase and adoption throughout many disciplines, such as geography or social psychology, is related to the rapid evolution of computers and its underlying capacity of calculus and computation, which facilitated the mathematical calculus approach of SNA.

\subsection{Current Situation in Education}

SNA was also adopted by other disciplines such as anthropology, biology, communication studies and economics, and more recently by education. In education SNA currently plays an emerging role in learning analytics, and many authors are applying its methods in order to understand and optimize social learning environments.

In the connectivism paradigm social technologies are the key drivers, as Siemens [7] explains as "social network analysis as an additional element in understanding learning models in a digital era". In his postulation of connectivism and later articles he argues the need for learning analytics methodologies to understand and optimize learning environments. Recently, Siemens defined a cycle that reflects the analytics in learning in which SNA appears as a must that should be applied at course level [14].

SNA not only fits in connectivism but in constructivism paradigms, as Thormann et al. [16] reflect in their article. The authors used the constructivism teaching approach to encourage student participation and critical thinking before the intervention of the instructor. In this aspect, SNA was used to do in-depth analysis of network structures and participation interaction.

Despite the above, SNA seems to be used mostly in research contexts. The lack of available SNA tools as a default by LMS providers are the main barrier for adaption in teaching environments, because there is no easy way for teachers to apply these methods in real time or during the course [12].

\section{SOCIAL NETWORK ANALYSIS FUNDAMENTALS}

There are many approaches or annotations to analyze and describe social network data mathematically and socially. Some of these annotations are: sociology, graph theoretic, algebra or exponential random graph models. Depending on the appropriateness, clarity or efficiency [17] one or another can be used. In this aspect, the graph theoretic notation suits centrality or dyadic and triadic methods best, the sociometric is more useful for the study of structural equivalence, and the statistical models are useful for going beyond these techniques because of the complexity of social behavior in social networks [15].

Considering these approaches and regarding the study of social learning environments, below there is a chart of those that are most used currently in the analysis of social learning networks in order to understand better the real use, which is explained at the end of this article.

\subsection{Sociology}

The basic foundation of SNA is the relation between two individuals. At the same time, these individuals are part of a social network where their interactions can be measured and hence understood as a group or groups that can be interconnected or isolated. In addition, the relation between individuals, groups and the whole network can be perceived in different manners, considering the relations as weak or strong. Hence, the main aim of SNA is to help understand the ties between individuals and inference, and the state of the network they are based upon.

Regarding the measures of a social network according to the ties that interconnect the individuals, they can be defined as following:

Table 1. Typical social network measures of ties [7]

\begin{tabular}{|c|c|}
\hline Measure & Definition \\
\hline Indirect links & $\begin{array}{c}\text { Path between two individuals is mediated by } \\
\text { one or more. }\end{array}$ \\
\hline Frequency & $\begin{array}{c}\text { How many times, or how often linkage } \\
\text { occurs. }\end{array}$ \\
\hline Stability & Existence of linkage over time. \\
\hline Multiplexity & $\begin{array}{l}\text { Extent to which two individuals are linked } \\
\text { together by more than one relation. }\end{array}$ \\
\hline Strength & $\begin{array}{l}\text { Amount of time, emotional intensity, intimacy } \\
\text { or reciprocal services. }\end{array}$ \\
\hline Direction & $\begin{array}{l}\text { Extent to which linkage occurs from one actor } \\
\text { to another. }\end{array}$ \\
\hline
\end{tabular}

According to each individual there are some other measures that also explain social interactions between them:

Table 2. Typical social network measure assigned to individuals [7]

\begin{tabular}{|c|c|}
\hline Measure & Definition \\
\hline Degree & Number of direct links with other individuals. \\
\hline In-degree & $\begin{array}{c}\text { Number of directional links to one individual } \\
\text { from others. }\end{array}$ \\
\hline Out-degree & $\begin{array}{c}\text { Number of directional links from one } \\
\text { individual to others. }\end{array}$ \\
\hline Closeness & $\begin{array}{c}\text { Extent to which an individual is close to, or } \\
\text { can easily reach all the others within the } \\
\text { network. }\end{array}$ \\
\hline Betweenness & $\begin{array}{c}\text { Extent to which an individual mediates, or } \\
\text { falls between any other two individual on the } \\
\text { shortest path between those two individuals. }\end{array}$ \\
\hline Centrality & $\begin{array}{c}\text { Extent to which an individual is central to a } \\
\text { network. }\end{array}$ \\
\hline Prestige & $\begin{array}{c}\text { Based on asymmetric relationships, } \\
\text { prestigious individuals are the object rather } \\
\text { than the source of relations. }\end{array}$ \\
\hline
\end{tabular}

At the same time the network as a whole can also be measured differently in its analysis:

Table 3. Measures for analyzing communities from a networks perspective [7]

\begin{tabular}{|c|c|}
\hline Measure & Definition \\
\hline $\begin{array}{c}\text { Central } \\
\text { connectors }\end{array}$ & $\begin{array}{c}\text { Central people often have the most direct } \\
\text { connections in a network and by virtue of this } \\
\text { can have a substantial impact on a } \\
\text { community. }\end{array}$ \\
\hline Brokers & $\begin{array}{c}\text { Network analysis also helps leaders find those } \\
\text { who, based on where they stand in the }\end{array}$ \\
\hline
\end{tabular}




\begin{tabular}{|c|c|}
\hline $\begin{array}{c}\text { Peripheral } \\
\text { players }\end{array}$ & $\begin{array}{c}\text { network, are disproportionately important in } \\
\text { holding the entire community together. }\end{array}$ \\
\hline $\begin{array}{c}\text { Network analysis can also help reveal loosely } \\
\text { connected or isolated members that often } \\
\text { represent under-utilized resources of a } \\
\text { community, because their skills, expertise, } \\
\text { and unique perspectives are not leveraged } \\
\text { efficiently. }\end{array}$ \\
\hline $\begin{array}{c}\text { Fragmentatio } \\
\text { n points }\end{array}$ & $\begin{array}{c}\text { The idea is never that you want everyone } \\
\text { connected to everyone else. Disconnections } \\
\text { are the gaps to be solved, so they can keep a } \\
\text { community as efficient as possible. }\end{array}$ \\
\hline $\begin{array}{c}\text { External } \\
\text { connectivity }\end{array}$ & $\begin{array}{c}\text { While internal connectivity is important, it is } \\
\text { also critical to consider the way a community } \\
\text { is connected externally in order to understand } \\
\text { how the entire network is learning and/or } \\
\text { impacting the work of others. }\end{array}$ \\
\hline
\end{tabular}

\subsection{Graph theory}

All the concepts above are sociology derived, but at the same time fully mathematically related. The graph theory [18] is the mathematical approach to social network analysis that has to be considered in order to comprehend social networks and the interactions between individuals in a quantitative manner. Both sociology and graph theory are considered complementary in the study and analysis of social networks. Thus, the use of both is encouraged, so that we can fully understand and optimize any social learning process.

The fundamentals of graph theory are based on the representation of a social network as a matrix, like the sociomatrix in sociometrics. The simplest and most common matrix is binary and called adjacency matrix. In this aspect, all the numerical approaches are based on a vertex-to-vertex matrix that is read as "row links to column".

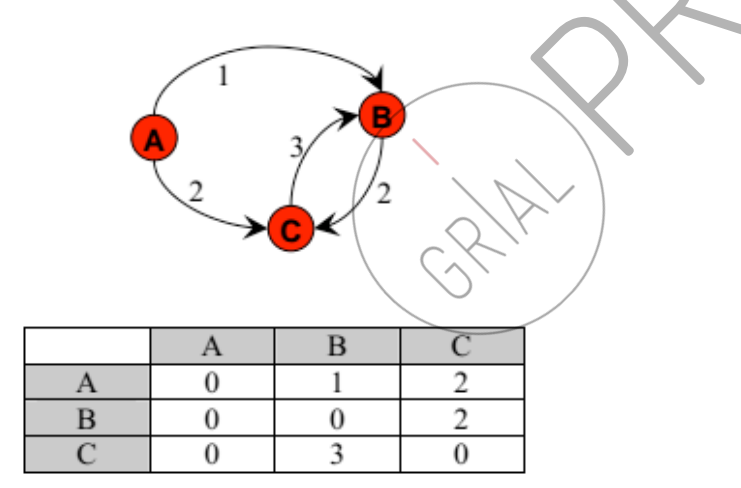

Figure 1. Graph and Social Network Matrix [19]

As in sociology, there are also some basic properties of graphs (network) and vertices (actors) in graph theory that can help us understand social interactions.

Table 4. Basic properties of graph theory [15].

\begin{tabular}{|c|c|}
\hline Property & Description \\
\hline Size & $\begin{array}{c}\text { Can be determined in terms of the number of } \\
\text { vertices. }\end{array}$ \\
\hline Density & $\begin{array}{l}\text { Is the number of edges in the network } \\
\text { expressed as a proportion of the number of all } \\
\text { possible edges. }\end{array}$ \\
\hline
\end{tabular}

\begin{tabular}{|c|c|}
\hline $\begin{array}{l}\text { Degree of } \\
\text { vertex }\end{array}$ & $\begin{array}{l}\text { In an undirected graph, the degree of a } \\
\text { vertex is the number of edges that such a } \\
\text { vertex has. } \\
\text { In directed graphs, we have to distinguish } \\
\text { between incoming edges (in-degree) and } \\
\text { outgoing edges (out-degree). }\end{array}$ \\
\hline Distance & $\begin{array}{l}\text { The distance between two vertices is the } \\
\text { minimum number of edges that it takes to go } \\
\text { from one to another. This is also known as the } \\
\text { geodesic distance. }\end{array}$ \\
\hline Eccentricity & $\begin{array}{l}\text { The largest geodesic distance of a vertex is } \\
\text { called its eccentricity - a measure of how far a } \\
\text { vertex is from the furthest other. }\end{array}$ \\
\hline Reachability & $\begin{array}{l}\text { A vertex is "reachable" by another if there is a } \\
\text { set of connections by which we can go from } \\
\text { the source to the target vertex, regardless of } \\
\text { how many others fall between them. }\end{array}$ \\
\hline Connectivity & $\begin{array}{l}\text { A graph is connected if it is possible to } \\
\text { establish a path from any vertex to another } \\
\text { vertex of a graph; otherwise the graph is } \\
\text { disconnected. }\end{array}$ \\
\hline Centrality & $\begin{array}{l}\text { There are three approaches to calculate the } \\
\text { centrality of a vertex: based on degree, on } \\
\text { closeness, and on betweenness (as in } \\
\text { sociology). }\end{array}$ \\
\hline
\end{tabular}

Considering these basic properties, similarities can be found between sociology and graph theories, such as some of the following:

Table 5. Similarities between sociological and mathematical network analysis concepts.

\begin{tabular}{|c|c|}
\hline Sociology & Graph Theory \\
\hline Network & Graph \\
\hline Individual & Vertex \\
\hline Relation & Edge \\
\hline Strength & Strength or weight \\
\hline Degree & Degree (undirected network) \\
\hline In-degree & In-degree (directed network) \\
\hline Out-degree & Out-degree (directed network) \\
\hline Closeness & Geodesic distance \\
\hline
\end{tabular}

\subsection{Exponential Random Graph Models (ERGM)}

ERGMs are considered to be recent techniques, as they were accepted by Wasserman and Pattison (1996) [14]. Before this, many authors had struggled, and defined the basis of ERGM [20] to obtain functional statistical models in order to infer the emergence and creation of social networks.

There are many methods that can measure properties of a network, their individuals, or a group of them by frequency, centrality or prestige. These are useful for analyzing, describing and understanding the observed network features that could answer some questions, for example. But in this aspect, new approaches were needed, such as the statistical ones, due to the complexity of social behavior and the need for models that allowed inferences in certain network substructures and their 
generation [15]. Currently, there are new probability models approaches [15] that allow better inference compared to the earliest models [20].

In relation to the methods mentioned above, sociology and graph theory are two methods that analyze and describe an observed network. ERGM works instead by measuring a limited set of known statistics from a network and then uses the distributions, such statistics, to generate random networks. These random networks are then compared to the observed network in order to check the goodness of fit.

\section{APPLICATION IN PRACTICE FOR LEARNING SUPPORT}

In the application of SNA methods in educational situations, different aims and objectives in relation to the level where they are applied can be distinguished, such as institutions, courses, teachers or students. Considering all levels, here are some researches and case studies that go beyond the practical use of SNA, controlling their usefulness in educational environments. In the following citations, teachers may find real use of SNA that could help them improve their teaching processes in social learning environments. In order to facilitate the lecture, the articles are organized according to the different situations that SNA could be useful in.

\subsection{Identify Patterns of Interaction or Friendships among students}

SNA permits us to study, describe and infer in the interactions between individuals in a social network, both on an individual basis and considering a group or groups of actors. This way, since there is more information about the relations between students in the social learning network of any course, the teacher can take action if any problem appears, such as a possible dropout, for example.

- $\quad$ Observing Emerging Student Networks on a Microblogging Service [21]: Examines the role of the microblogging social network Twitter. The results of this study found that Twitter is easy for students to use and suggest models for future use of microblogging services.

- Collaborative learning processes in an asynchronous environment: an analysis through discourse and social networks [22]: The main objective of the authors is to describe the processes of collaborative knowledge construction and the relevance of many-to-many communication in collective case resolution, in asynchronous writing contexts. The results lead to the hypothesis that many-to-many communication is more important in a collective knowledge generation process than in dyadic or triadic communication.

- A study of the relationship between student social networks and sense of community [23]: The authors evaluated an individual's level of sense of community and their position within the social network in the classroom. The article presents the findings from a study investigating the relationship between a student's position in a social network and their perceived sense of community.

- Análisis de redes sociales en la educación a distancia: estudio de caso de una metodología alternativa para estudiar la interacción social en ambientes digitales de aprendizaje [24]: This study denotes a mixed approach, using both social network analysis and research methodologies, such as statistics or interviews, in order to get a more complete comprehension of social educational situations.

- $\quad$ Semantic Social Network Analysis [25]: Proposes leveraging semantic web technologies to merge and exploit the best features of each domain in order to understand interactions between individuals.

\subsection{Identify or Improve Characteristics of students}

The study of a social network can detect both positive and negative situations, but also abilities or characteristics of students that could be controlled and improved.

- Online Learner Self-Regulation: Learning Presence Viewed through Quantitative Content and Social Network Analysis [26]: The authors propose that the combination of quantitative content analysis (QCA) and SNA may allow for a compatible research approach, highlighting the qualities of both form and context of interactions in online learning environments. In the study, learning presence was used to refer to iterative processes of forethought and planning, monitoring and adapting strategies for learning, reflecting on results that successful students use to regulate their learning in online, interactive environments. The authors concluded that it seems probable that the capacity to self-regulation in online environments results in more relevant or more sophisticated discourses, making students with better learning presence more attractive companions for their classmates.

Wiring Role Taking in Collaborative Learning Environments. Can SNA and Semantic Web improve CSCL script? [27]: This work proposes the use of SNA in order to evaluate the expertise level of a learner when he/she is acting, with an assigned role, within the execution of a collaborative script. Finally, a design of web learning environment is proposed in order to allow a teacher to define ongoing users profiles, based on indices proposed in the article, so that group collaboration can be as efficient as possible.

- Formación en red de habilidades de investigación en la Universidad Estatal a Distancia de Costa Rica [28]: The study conducted a virtual social network aimed to develope research skills among the students. The authors concluded that SNA is an efficient tool for the identification of different users in virtual social networks.

\subsection{Optimize Social Learning Environments}

One of the aims of SNA in education is to optimize the educational roles and personalize the students' learning processes. SNA helps discover better ways to do this, as shown by the following authors.

- Investigating the potential of using social network analysis in educational evaluation [29]: The aim of this method is to use data from teacher collaboration within schools to map the distribution of expertise and resources that are needed to create reforms.

- Asynchronous Discussion Forum: Integration of Content Analysis and Social Network Analysis [30]: The authors denote that integration of SNA may offer advantages in which transcript and structural network of interaction can be analyzed during discussion.

- $\quad$ Speech and Social Network Analysis in the Study of On-line Cooperative Learning in University Forums [31]: The aim of 
this research is to examine the asynchronic context by analyzing speech and the depth and width of social networks that emerge, in order to shape quality indicators for these learning methods.

- Using social networks and communities of practice to support information systems implementation [32]: This case study demonstrates a new approach to information systems based on social capital and community of practice, and illustrates how it can be conducted in practice.

\section{CONCLUSIONS}

The implementation of social network analysis in learning environments is still recent, compared to its use in other contexts. Since the $1^{\text {st }}$ International Conference on Learning Analytics and Knowledge in 2011 [33] coined the term Learning Analytics, it appears that there is a growing awareness of the use of social network analysis. In this aspect, researchers are applying social theories to educational situations in order to analyze, describe and infer from the relations between individuals, both from an individual point of view and from a group point of view. Hence, the aim of using SNA is to optimize learning processes at all levels, from institution to students.

Despite the aforementioned, current social analysis techniques do not differ very much from those that were originally considered sociometrics or graph theories, for example. The practical use of SNA is based on those methods and paradigms, and it seems to be enough for the analysis of social networks. In this regard, and considering a possible renovation of SNA methods, it seems that only the statistical approaches are suffering some innovation or reformulation, among all the available methods and techniques of statistical analysis of social networks.

Finally, here is an excerpt of the SNA research in order to reflect recent work that has been done in this social context. We wish to highlight the importance of SNA for the optimization of social learning environments, and especially encourage the integration of the available methods in order to analyze social networks as a default feature of current available LMSes. At the same time, we encourage teachers to use these techniques, and to researchers to continue enlightening the educational community with the potentials of SNA in the optimization of social environments in education.

\section{REFERENCES}

[1] Media Legislation Reports. The maturing of the MOOC: Literature review of Massive Open Online Courses and other forms of Online Distance Learning (BIS Research Paper Number 130). http://goo.gl/twgmen (06-07-2014).

[2] Baggaley, J., 2013. REFLECTION: MOOC rampant. Distance Education, 368-378.

[3] Arcos Gracía, F., Ortega Gil, P., and Amilburu Osinaga, A., 2012. Social learning in formal education through peer collaborative networks and activities: research results and hazards. http://goo.gl/U4Kz9a (07-07-2014).

[4] Van Harmelen, M. and Workman, D., 2012. Analytics for Learning and Teaching. CETI Analytics Series, 1, 3. http://goo.gl/q5Egdc.

[5] U.S. Department of Education, Office of Educational Technology, 2012. Enhancing Teaching and Learning Through Educational Data Mining and Learning Analytics: An Issue Brief. Washington, D.C. http://goo.gl/1OHggU.
[6] Adkins, D., 2008. The Use of Social Network Analysis to Measure Knowledge Sharing in the New York State Project Management Community of Practice. ProQuest.

[7] Siemens, G., 2005. Connectivism: A learning theory for the digital age. International journal of instructional technology and distance learning 2, 1, 3-10.

[8] Reports: Forum Graph. http://goo.gl/6MLG1A (10-11-2013).

[9] SNAPP, Social Networks Adapting Pedagogical Practice. http://goo.gl/iTGE2V (01-07-2014).

[10] SNAP: Stanford Network Analysis Project. http://goo.gl/vC0GKj (01-07-2014).

[11] Gephi (nd). Gephi, an open source graph visualization and manipulation software. http://goo.gl/A1ORRj (10-11-2013)

[12] Feldstein, M., 2010. Social Network Analysis and the LMS. http://goo.gl/J7OeV7 (01-07-2014).

[13] Siemens, G. and Long, P., 2011. Penetrating the fog: Analytics in learning and education. Educause Review 46, 5, 30-32.

[14] Robins, G., Pattison, P., Kalish, Y. and Lusher, D., 2007. An introduction to exponential random graph models for social networks. Social Networks 29, 173-191. DOI= http://dx.doi.org/10.1016/j.socnet.2006.08.002.

[15] Passmore, D. L., 2011. Social Network Analysis: Theory and Applications. http://goo.gl/LhPpwv (01-07-2014).

[16] Thormann, J., Gable, S., Fidalgo, P.S., and Blakeslee, G., 2013. Interaction, critical thinking, and social network analysis (SNA) in online courses. The International Review of Research in Open and Distance Learning 14, 3, 294-318.

[17] Wasserman, S., 1994. Social network analysis: Methods and applications. Cambridge university press.

[18] Van Steen, M., 2010. An Introduction to Graph Theory and Complex Networks. http://goo.gl/GCQYOQ (07-07-2014).

[19] Izquierdo, L.R. and Hanneman, R.A., 2006. Introduction to the formal analysis of social networks using mathematica. University of California, Riverside.

[20] Skyler J., and Bruce A., 2010. Inferential Network Analysis with Exponential Random Graph Models. DOI= http://dx.doi.org/10.1093/pan/mpq03.

[21] Badge, J., Johnson, S., Moseley, A. and Cann, A., 2011, Observing emerging student networks on a microblogging service. MERLOT Journal of Online Learning and Teaching 7, 1, 91-98.

[22] Tirado, R., Aguaded, I., and Hernando, A., 2011. Collaborative Learning Processes in an Asynchronous Environment: An Analysis through Discourse and Social Networks. Online Submission 2, 1, 115-146.

[23] Dawson, S., 2008. A study of the relationship between student and social networks and sense of community. Educational Technology and Society 11, 3, 224-238.

[24] Montenegro, M., 2012. Análisis de redes sociales en la educación a distancia: estudio de caso de una metodología alternativa para estudiar la interacción social en ambientes digitales de aprendizaje. Itinerario Educativo xxvi, 59, 177 196.

[25] Erétéo, G., Gandon, F., Buffa, M., and Corby, O., 2009. Semantic Social Network Analysis. In Proceedings of the 
WebSci'09: Society On-Line, 18-20 March 2009, Athens, Greece.

[26] Shea, P., Hayes, S., Smith, S.U., Vickers, J., Bidjerano, T., Gozza-Cohen, M., Jian, S.-B., Pickett, A., Wilde, J., and Tseng, C.-H., 2013. Online learner self-regulation: Learning presence viewed through quantitative content-and social network analysis. The International Review of Research in Open and Distance Learning 14, 3, 427-461.

[27] Capuano, N., Mangione, G.R., Mazzoni, E., Miranda, S., and Orciuoli, F., 2014. Wiring Role Taking in Collaborative Learning Environments. SNA and Semantic Web can improve CSCL script? International Journal of Emerging Technologies in Learning (iJET) 9, 7, pp. 30-38.. DOI= http://dx.doi.org/10.3991/ijet.v9i7.3719.

[28] Segura-Castillo, A. and Vázquez-Olguín, S., 2012. Formación en red de habilidades de investigación en la Universidad Estatal a Distancia de Costa Rica. Cuadernos de Investigación UNED 4, 1, 117-127.
[29] Penuel, W. R., Sussex, W., Korbak, C., and Hoadley, C., 2006. Investigating the potential of using social network analysis in educational evaluation. American Journal of Evaluation 27, 4, 437-451.

[30] Erlin, Yusof, N., and Abdul, A., 2013. Asynchronous Discussion Forum: Integration of Content Analysis and Social Network Analysis. http://goo.gl/5BqXWm (01-072014).

[31] Hernando, A., Tirado, R., and Aguaded, J.I., 2011. Aprendizaje cooperativo on-line a través de foros en un contexto universitario : un análisis del discurso y de las redes. Estudios sobre Educación. 20, 49-71.

[32] Hamre, L., and Vidgen, R., 2008. Using social networks and communities of practice to support information systems implementation. In 16th European Conference on Information Systems, ECIS 2008.

[33] 1st International Conference on Learning Analytics and Knowledge of 2011. LAK'11. http://goo.gl/CwKtCX (01-072014)

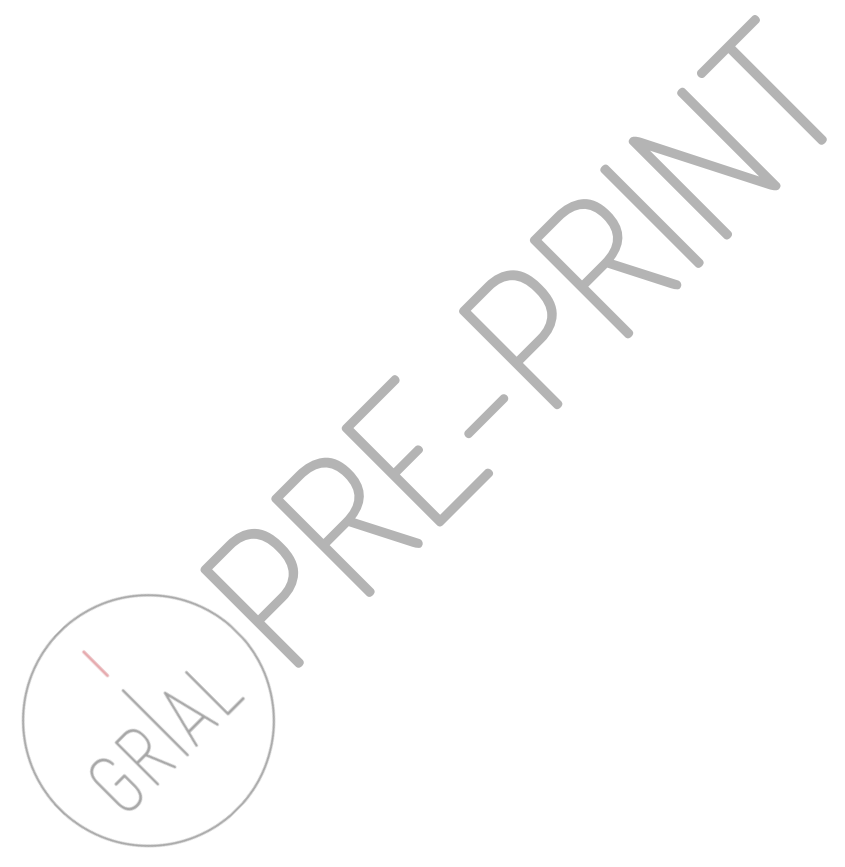

